\title{
Congenital choledochal cyst in a toddler - case report and literature review
}

\author{
Smaranda Diaconescu ${ }^{1,2}$, Silvia Strat ${ }^{2}$, Andreea Nichita ${ }^{2}$, Gabriela Paduraru ${ }^{1,2}$, \\ Gabriela Ghiga ${ }^{1}$, Oana Maria Rosu ${ }^{2}$, Ana Maria Scurtu' ${ }^{2}$, Cristina Alexa ${ }^{2}$, \\ Petru Plamadeala², Eduard Vasile Rosu², Lorenza Donea ${ }^{2}$ \\ 1"Grigore T. Popa" University of Medicine and Pharmacy, lasi \\ ${ }^{2}$ Clinic of Pediatric Gastroenterology, "Sf. Maria" Children's Hospital, lasi
}

\begin{abstract}
Congenital choledochal cysts are more frequently diagnosed in children under the age of 10 , occurring prevailingly in female patients. We are presenting a case of choledochal cyst in a 7-month-old male baby, which had a sudden onset with scleral-cutaneous jaundice and lack of appetite. Abdominal ultrasound revealed a transonic, hyperreflective formation located in the topography of the main bile duct, dilated intrahepatic bile ducts, and laboratory tests revealed a severe syndrome of hepatic cytolysis and cholestasis. The diagnosis was confirmed using cholangiopancreatic MRI performed in an emergency regime and required surgical intervention. Therefore, the differential diagnosis of cholestasis syndromes must rule out choledochal cyst irrespective of the patient's age due to the complications and risk of malignization.
\end{abstract}

Keywords: choledochal cyst, jaundice, cholestasis, infant

\author{
Abbreviations \\ AP: Alkaline phosphatase \\ APTT: Activated partial thromboplastin time \\ CCC: Congenital choledochal cysts \\ CRP: $C$ reactive protein \\ DB: Direct bilirubin \\ ERCP: Endoscopic retrograde cholangiopancreatography \\ GGT: Gamma-glutamyl transpeptidase \\ GOT: Glutamic oxaloacetic transaminase
}

\section{INTRODUCTION}

The congenital choledochal cyst (CCC) is a malformation transmitted in an autosomal recessive manner, expressing a genetic defect in the structure of the biliary tree and is included in the category of disorders that can cause biliary cirrhosis and portal hypertension by means of biliary stasis (1).

This pathology is rarely encountered, with the international medical literature reporting only 1,532 cases by year 1984, and approximately 2,430 by year 2000 , respectively. Increased emphasis is
GPT: Alanine aminotransferase IHBD: Intrahepatic biliary ducts MCHC: Mean corpuscular hemoglobin concentration MCV: Mean corpuscular volume (PA/T/CC): Postero-anterior/transverse/cranio-caudal PT: Prothrombin time

TB: Total bilirubin

placed on the importance of ultrasound, and for positive diagnosis on confirmation with MRI cholangiography (2).

Congenital choledochal cysts can be clinically silent (discovered incidentally, while performing a routine abdominal ultrasound or during surgery in the upper abdomen) or can be expressed clinically via the classic triad of symptoms described by Sénéque and Tailhefer (pain in the right upper quadrant, scleral-cutaneous jaundice, palpable tumoral formation in the right upper quadrant), as well as directly through complications such as biliary lithiasis, angiocholitis, acute pancreatitis (which are 
predominant in Todani type III and type IV A), or phenomena of portal hypertension (3).

We are presenting a case of choledochal cyst in a 7 months old baby, where early diagnosis allowed for prompt surgical intervention.

\section{CLINICAL CASE}

Seven months old male patient without any significant medical history, is admitted into the Pediatric Gastroenterology clinic via transfer from a regional hospital, where he was given an abdominal ultrasound on account of scleral-cutaneous jaundice that had occurred approximately 4 days before; the ultrasound revealed a cyst in the $\mathrm{V}^{\text {th }}$ segment of the liver.

Upon admission, the baby presented with scleral-cutaneous jaundice, dysmorphic facies, preauricular and perioral fibrochondroma, normal cardio-pulmonary auscultation, mild abdominal distension, depressible abdomen, mobile with breathing, no palpable tumoral formations, acholic stools, present diuresis, hyperchromic urine, no signs of meningeal irritation.

Paraclinical tests revealed eosinophilia, hypochromic normocytic anemia, inflammatory syndrome, hepatic cytolysis syndrome (transaminases were 5 times the normal values), hyperammonemia (double the normal values), hyperbilirubinemia $(\mathrm{DB}=6.95 \mathrm{mg} / \mathrm{dl}, \mathrm{TB}=8.77 \mathrm{md} / \mathrm{dl})$, hypercholesterolemia, hypertriglyceridemia, GGT=1,869 U/1, $\mathrm{AP}=1,695 \mathrm{U} / 1$, and slightly prolonged $\mathrm{PT}$. protein electrophoresis revealed fraction alpha 1 with high globulin and low gamma globulins.

TABLE 1. Paraclinical profile

\begin{tabular}{|l|c|c|}
\hline Parameter & Registered value & Reference interval \\
\hline Eosinophils & $0.42 * 10^{5} \mu \mathrm{l}$ & $0-0.3 * 105 \mu \mathrm{l}$ \\
\hline Eosinophils \% & $5.5 \%$ & $0-5 \%$ \\
\hline Hemoglobin & $10.5 \mathrm{~g} / \mathrm{dl}$ & $11.4-14 \mathrm{~g} / \mathrm{dl}$ \\
\hline Hematocrit & $30.8 \%$ & $33-41 \%$ \\
\hline MCV & $70.8 \mathrm{fL}$ & $70-85 \mathrm{fL}$ \\
\hline MCHC & $24.1 \mathrm{pg}$ & $25-30 \mathrm{pg}$ \\
\hline APTT & 22.3 seconds & $23-34$ seconds \\
\hline PT & 17.4 seconds & $13-17$ seconds \\
\hline GOT & $216 \mathrm{U} / \mathrm{l}$ & $5-35 \mathrm{U} / \mathrm{l}$ \\
\hline GPT & $210 \mathrm{U} / \mathrm{l}$ & $5-38 \mathrm{U} / \mathrm{l}$ \\
\hline GGT & $1,869 \mathrm{U} / \mathrm{l}$ & $7-55 \mathrm{U} / \mathrm{l}$ \\
\hline AP & $1,695 \mathrm{U} / \mathrm{l}$ & $40-600 \mathrm{U} / \mathrm{l}$ \\
\hline TB & $8.77 \mathrm{mg} / \mathrm{dl}$ & $0.25-1 \mathrm{mg} / \mathrm{dl}$ \\
\hline DB & $6.95 \mathrm{mg} / \mathrm{dl}$ & $0-0.25 \mathrm{mg} / \mathrm{dl}$ \\
\hline IB & $1.82 \mathrm{mg} / \mathrm{dl}$ & \\
\hline Total cholesterol & $355 \mathrm{mg} / \mathrm{dl}$ & $100-200 \mathrm{mg} / \mathrm{dl}$ \\
\hline Triglyceride & $256 \mathrm{mg} / \mathrm{dl}$ & $40-150 \mathrm{mg} / \mathrm{dl}$ \\
\hline Total proteins & $57.94 \mathrm{~g} / \mathrm{l}$ & $46-68 \mathrm{~g} / \mathrm{l}$ \\
\hline
\end{tabular}

\begin{tabular}{|l|c|c|}
\hline Parameter & Registered value & Reference interval \\
\hline Alpha1 & $5.3 \%$ & $1.4-4 \%$ \\
\hline Gamma & $4.17 \mathrm{~g} / \mathrm{l}$ & $5.84-13.2 \mathrm{~g} / \mathrm{l}$ \\
\hline Creatinine & $0.91 \mathrm{mg} / \mathrm{dl}$ & $0.1-0.5 \mathrm{mg} / \mathrm{dl}$ \\
\hline Urea & $6 \mathrm{mg} / \mathrm{dl}$ & $10-40 \mathrm{mg} / \mathrm{dl}$ \\
\hline Ammonia & $81.24 \mu \mathrm{mol} / \mathrm{l}$ & $0-47 \mu \mathrm{mol} / \mathrm{l}$ \\
\hline CRP & $15.9 \mathrm{mg} / \mathrm{dl}$ & $0-5 \mathrm{mg} / \mathrm{l}$ \\
\hline IgM & $27 \mathrm{mg} / \mathrm{dl}$ & $36-104 \mathrm{mg} / \mathrm{dl}$ \\
\hline
\end{tabular}

We tested for anti-cytomegalovirus IgG antibodies, anti-Toxoplasma gondii antibodies, Heterophile antibody test, anti-Epstein Barr virus IgG antibodies, hepatitis $B$ antigen, anti-hepatitis $C$ virus antibodies, anti-hepatitis A virus IgM antibodieswith negative results.

Abdominal ultrasound reveals liver with normal size, with homogeneous structure, normal reflectivity; no gallbladder lithiasis; transonic formation with hyperreflective declival deposit sized $5.33 / 3.31 / \mathrm{cm}$ and located on the topography of the gallbladder; normal portal vein; dilated intrahepatic bile ducts; $0.9 \mathrm{~cm}$ thick layer of fluid below the liver; normal kidneys upon ultrasound; pancreas could not be visualized; spleen with homogeneous structure; partial repletion of the urinary bladder, with transonic contents (Fig. $1 \mathrm{~A}, \mathrm{~B}, \mathrm{C}$ ).
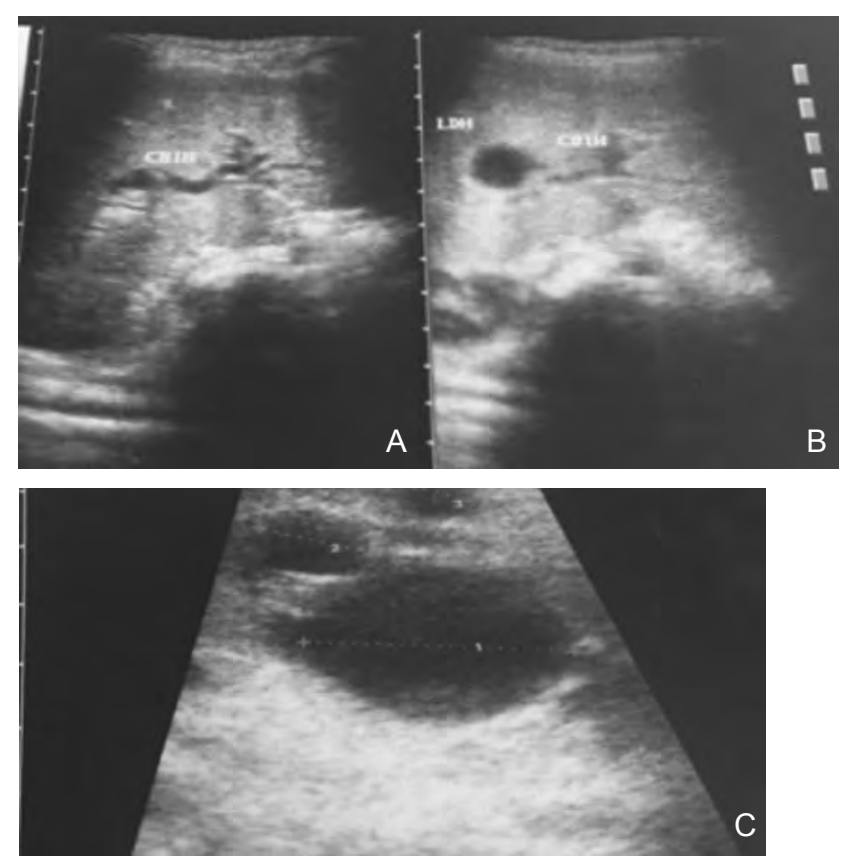

FIGURA 1. A, B, C. Ultrasound aspects

We initiated treatment with arginine, ursodeoxycholic acid and liver protectors.

The cholangiopancreatic MRI performed in an emergency regime described an expansive oval formation, with thin walls, contents with bile-type signal, no take-up of the contrast agent, located in the 
liver hilum, sized 36/35/60 $\mathrm{mm}$ (PA/T/CC) Choledochocele under observation (Fig. 2).

The formation originates in the bifurcation of the common bile duct, exercises a mass effect on the gallbladder, pancreatic head and duodenal flexure; Dilated cystic duct in the distal portion up to 9 $\mathrm{mmm}$; Dilated IHBD up to $4.3 \mathrm{~mm}$ in the main left branch.
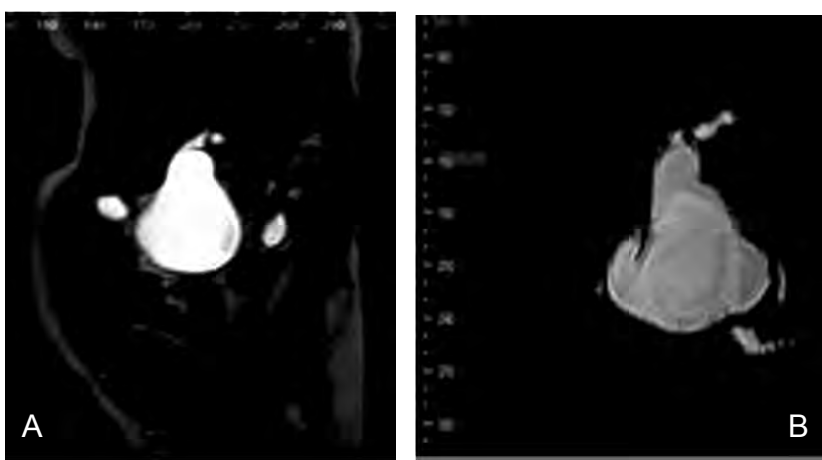

FIGURA 2. $A$ and B - Cholangiopancreatic MRI aspects

The patient was transferred into the pediatric surgery department in order to perform the surgical intervention.
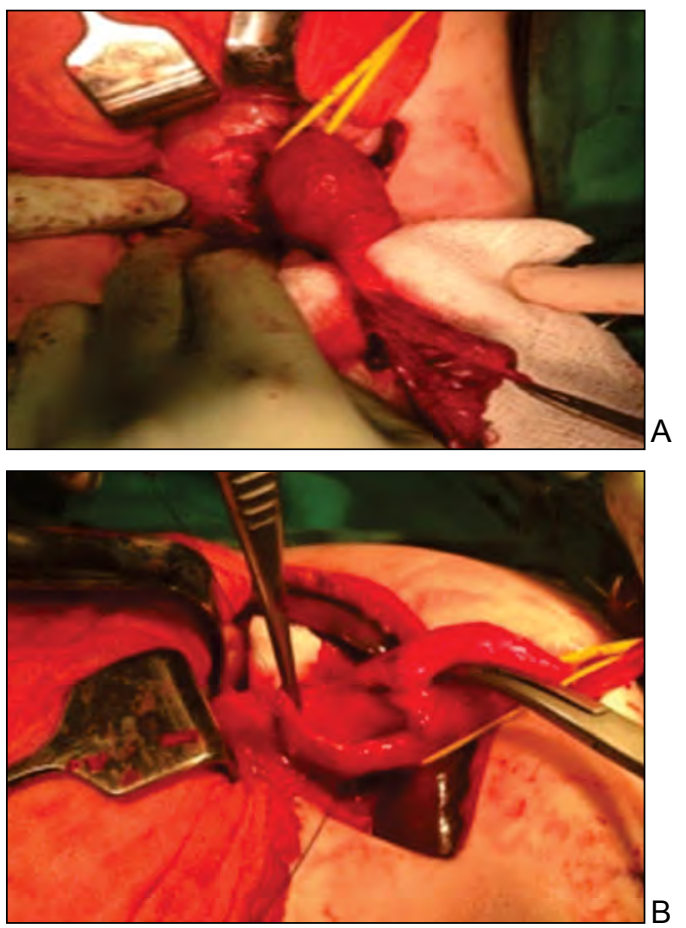

FIGURA 3. $A$ and $B$ - Intraoperative aspects

The procedure comprised Kocher incision, cyst ablation, cholecystectomy, biliodigestive derivation, Roux-en-Y lateral-terminal anastomosis and liver biopsy (Fig. 3. A and B).

After surgery, the patient received packed red blood cell infusion, then albumin; treatment was started with antibiotics in a double association (metronidazole and piperacillin/tazobactam), pantoprazole and symptomatic treatment. Transaminase values returned to normal and patient maintained a mild hyperbilirubinemia based on the direct bilirubin; the inflammatory syndrome went into remission and the other biological parameters normalized.

The result of the anatomopathological examination confirmed the presence of the choledochal cyst, and the liver biopsy revealed a cholestatic liver and pericentrolobular inflammation.

The postoperative evolution was favorable, without complications, the baby being discharged on the $11^{\text {th }}$ day after the surgery. The one-month follow-up reveals a normalized clinical and biological profile and the absence of pathological images on the ultrasound.

\section{DISCUSSIONS}

There are several etiopathogenic theories, including the embryologic theory (Yotsyanagi, 1936embryogenesis defect in the weeks 8-12 of gestation), the theory of nervous intramural agenesis, the theory of partial biliary atresia, theory of high biliary-pancreatic junction (a longer common duct allows the reflux of pancreatic secretion, with the enzymatic destruction of the biliary mucosa, favoring dilation) associated with a higher risk of malignization, and the theory of distal obstruction of the common bile duct by a fibrous nodule, valve disorder or flexure (1).

One study reported a sample of 14 children with a mean age of 5.2 years (between 1 and 15 years old) (2). Romanian authors report a sample of patients aged 9 months to 10 years old, with a mean age of 2 years and 4 months (1). In our case, the baby was diagnosed when he was 7 months old, which is relatively early compared to the reported mean age of diagnosis.

Gender distribution in the studied samples was biased towards female patients, which represented between $100 \%$ and $71.42 \%$, respectively, while Poddar described equal gender distribution $(1,2,4)$.

The authors are reporting a sample of 14 cases where the classic triad of symptoms (jaundice, abdominal pain and palpable mass) was encountered only in two cases, with scleral-cutaneous jaundice and abdominal pain being predominant in the others. (2) In our case, the symptomatology only included jaundice, acholic stools and hyperchromic urine, as abdominal pain is difficult to assess in toddlers.

ERCP is the method of choice for the minimally invasive diagnosis and management of $\mathrm{CCC}$ and 
associated choledochal and intracystic lithiasis, but its utility is limited in small children. Thus, ultrasound remains the screening method of choice for biliary tree malformations, while cholangiography (MRI or intraoperative) is the first intent method for confirmation (5).

Some authors report that the diameter of the common bile duct should be less than $1.6 \mathrm{~mm}$ in infants and less than $3 \mathrm{~mm}$ in children, while others support the fact that sonographic findings of a visible intrahepatic biliary duct and common biliary duct's diameter wider than $2 \mathrm{~mm}$ in infants, wider than $4 \mathrm{~mm}$ in children, and wider than $7 \mathrm{~mm}$ after adolescence represent pathological findings (6). In our case, intrahepatic biliary duct's dilatation up to $4.3 \mathrm{~mm}$ was observed, placing it outside the physiological aspects, no matter which criteria is being considered.

Lee describes in his series the mean diameter of $\mathrm{CCC}$ as $21.4+/-12.1 \mathrm{~mm}$ (5). In our case, CCC dimensions were $36 / 35 / 60 \mathrm{~mm}$, above the mean described diameters.

As for treatment, it was delivered surgically in $100 \%$ of the cases, of which $57.1 \%$ of cases underwent Roux-en-Y biliary-jejunal anastomosis and $42.9 \%$ of cases underwent biliary-duodenal anastomosis, with a statistically insignificant difference both in the rate of complications, and in the duration of hospitalization between the two subsamples reported by Hector Silva-Baez ( $\mathrm{P}=0.71 \%)$ (2).

In the sample mentioned above, the cyst removal was followed by restoration of the biliary circuit via Roux-en-Y biliary-jejunal anastomosis in 6 cases, and biliary-duodenal anastomosis in 2 cases. Reported evolution was favorable, noting a normal anthropometric development (2).

As for treatment, foreign authors believe cyst excision and Roux-en-Y biliary-jejunal anastomosis is the procedure of choice, offering the best results, a procedure we also used for our patient, with a postoperative evolution free of complications. Internal drainage of the cyst (cysto-duodenal anastomosis) was used in the past, but this procedure resulted in high morbidity rates due to potential complications (stenosis, biliary stasis, biliary lithi- asis, cholangitis), as well as due to the high risk of incidence of bile duct carcinoma (7).

Cyst excision is not always easy to do; in small children, dissecting and separating the cyst from the hepatic artery and the portal vein is usually easy, but difficulties appear when there are adhesions and when the local morphology is modified. The laparoscopic surgical solution is recommended for treating CC particularly for Todani type I, this one being mentioned in the literature (8).

Poddar and colleagues reports a predominance of Todani types I and IV A in the studied patient sample. Also, in this sample they registered 6 cases of secondary biliary cirrhosis, 2 cases of extrahepatic biliary duct atresia and one case of congenital liver fibrosis (4). In this case, the correlation of imaging and intraoperative data determines the diagnosis of congenital choledochal cysts Todani type I, the most frequent type of CCC. Liver biopsy indicated pericentrolobular inflammation, stressing the importance of early management for CCC, before the onset of liver fibrosis.

\section{CONCLUSIONS}

Congenital biliary duct cyst is rarely encountered in our geographic area, but this possibility must be considered in the differential diagnosis of biliary syndrome with recurring evolution in children.

The symptomatology is varied, particularly in toddlers, where the classic triad is almost impossible to outline. Clinical suspicions must always be followed by imaging investigations, with early diagnosis and management allowing for favorable evolutions and minimum complications.

Radical interventions are not always possible owing to the technical difficulties determined by changes in the local morphology, as well as by alteration of the patients' status. Thus, the therapeutic approach must be adapted to every single patient, and surgical patients require lifelong monitoring due to the possibility of developing late-onset complications (angiocholitis, lithiasis, biliary cirrhosis, cyst rupture, acute pancreatitis, mass effect on near-by structures, malignancy).

\section{REFERENCES}

1. Aprodu G, lonescu S, Mihaială D, Botez C. Chistul congenital de coledoc - modalităţi de diagnostic şi tratament. Educaţie medicală continuă - Chirurgie generală. 2005

2. Hector Silva-Baez et al. Treatment of choledochal cyst in a pediatric population. A single institution experience of 15-years. Case series. Ann Med Surg (Lond). 2016 Feb; 5: 81-85.

3. Soares KC, Arnaoutakis DJ, Kamel I, Rastegar N, Anders R, Maithel S. Choledochal cysts: Presentation, clinical differentiation, and management. J. Am. Coll. Surg. 2014;219(6):1167-1180.

4. Poddar U, Vijayaraghavan P1, Lal R, Sikora SS, Yachha SK. Experience with choledochal cysts in infants. Pediatr Surg Int. 2006 Oct;22(10):803-7. 
5. Ouaïssi M et al. Todani Type II Congenital Bile Duct Cyst: European Multicenter Study of the French Surgical Association and Literature Review. Ann Surg. 2015 Jul;262(1):130-8.

6. Hung-Chang Lee. Ultrasonography of Choledochal Cysts in Children. J Med Ultrasound. 2007;15:191-196.

7. Ragot $E$ et al. Pancreaticobiliary Maljunctions in European Patients with Bile Duct Cysts: Results of the Multicenter Study of the French Surgical Association (AFC). World J Surg. 2017 Feb;41(2):538-545.
8. Gadelhak N, Shehta A, Hamed H. Diagnosis and management of choledochal cyst: 20 years of single center experience. World J. Gastroenterol. 2014;20(22):7061-7066.

Conflict of interest: none declared Financial support: none declared 